\title{
FORMALIZATION CODING METHODS OF INFORMATION UNDER TOROIDAL COORDINATE SYSTEMS
}

Riznyk V. V. - Dr. Sc., Professor, Professor of the Automatized Control System Department, Lviv Polytechnic National University, Lviv, Ukraine.

\begin{abstract}
Contents. Coding and processing large information content actualizes the problem of formalization of interdependence between information parameters of vector data coding systems on a single mathematical platform.

Objective. The formalization of relationships between information parameters of vector data coding systems in the optimized basis of toroidal coordinate systems with the achievement of a favorable compromise between contradictory goals.

Method. The method involves the establishing harmonious mutual penetration of symmetry and asymmetry as the remarkable property of real space, which allows use decoded information for forming the mathematical principle relating to the optimal placement of structural elements in spatially or temporally distributed systems, using novel designs based on the concept of Ideal Ring Bundles (IRB)s. IRBs are cyclic sequences of positive integers which dividing a symmetric sphere about center of the symmetry. The sums of connected sub-sequences of an IRB enumerate the set of partitions of a sphere exactly $R$ times. Two-and multidimensional IRBs, namely the "Glory to Ukraine Stars", are sets of $t$-dimensional vectors, each of them as well as all modular sums of them enumerate the set node points grid of toroid coordinate system with the corresponding sizes and dimensionality exactly $R$ times. Moreover, we require each indexed vector data "category-attribute" mutually uniquely corresponds to the point with the eponymous set of the coordinate system. Besides, a combination of binary code with vector weight discharges of the database is allowed, and the set of all values of indexed vector data sets are the same that a set of numerical values. The underlying mathematical principle relates to the optimal placement of structural elements in spatially and/or temporally distributed systems, using novel designs based on $t$ dimensional "star" combinatorial configurations, including the appropriate algebraic theory of cyclic groups, number theory, modular arithmetic, and IRB geometric transformations.

Results. The relationship of vector code information parameters (capacity, code size, dimensionality, number of encodingvectors) with geometric parameters of the coordinate system (dimension, dimensionality, and grid sizes), and vector data characteristic (number of attributes and number of categories, entity-attribute-value size list) have been formalized. The formula system is derived as a functional dependency between the above parameters, which allows achieving a favorable compromise between the contradictory goals (for example, the performance and reliability of the coding method). Theorem with corresponding corollaries about the maximum vector code size of conversion methods for $t$-dimensional indexed data sets "category-attribute" proved. Theoretically, the existence of an infinitely large number of minimized basis, which give rise to numerous varieties of multidimensional "star" coordinate systems, which can find practical application in modern and future multidimensional information technologies, substantiated.

Conclusions. The formalization provides, essentially, a new conceptual model of information systems for optimal coding and processing of big vector data, using novel design based on the remarkable properties and structural perfection of the "Glory to Ukraine Stars" combinatorial configurations. Moreover, the optimization has been embedded in the underlying combinatorial models. The favorable qualities of the combinatorial structures can be applied to vector data coded design of multidimensional signals, signal compression and reconstruction for communications and radar, and other areas to which the GUS-model can be useful. There are many opportunities to apply them to numerous branches of sciences and advanced systems engineering, including information technologies under the toroidal coordinate systems. A perfection, harmony and beauty exists not only in the abstract models but in the real world also.
\end{abstract}

KEYWORDS: elegant symmetry and asymmetry ensemble, relationship, information redundancy, combinatorial configuration, optimum vector data coding, code size, basis, trade-off.

\section{ABBREVIATIONS}

BVD is a big vector data;

ESAE is a Elegant Symmetry and Asymmetry Ensemble;

IRB is an Ideal Ring Bundle;

GUS is a "Glory to Ukraine Star" configuration;

OLAP is an online analytical processing;

OSR is an Optimum Structural Relationship;

GF is a Galois field;

$\mathrm{PG}$ is a projective geometry;

\section{NOMENCLATURE}

$\alpha_{\min }$ is a minimal angular distance;

$\alpha_{\max }$ is a maximal angular distance;

$k_{i t}$ is an $i$-th integer of $t$-tuple;

$m_{i}$ is a number of categories of $i$-th attribute, as well as a number of reference points on $i$-th ring axis in a toroidal coordinate system;

(C) Riznyk V. V., 2021

DOI 10.15588/1607-3274-2021-2-15
$N$ is a general number of central angles multiple of $\alpha_{\text {min }}$;

$n$ is a capacity of toroidal coordinate system basis;

$P_{\max }$ is a code size of $t$-dimensional vector data array;

$R$ is a number coding of the same vector data array;

$S$ is an order of rotational symmetry, a number of star-code combinations, as well as a number of nodal points in toroid coordinate system;

$t$ is a dimension of vector data array, number of attributes, as well as a number of significant digits of $t$-dimensional code.

\section{INTRODUCTION}

One of the key directions for development of modern information technologies is the design of multidimensional control systems of technical and technological objects, management of multidimensional systems and exchange of big vector data in information and communication networks, coding of information sources and other 
practically important scientific and technical problems of today.

The object of study is the process of vector data coding and processing signals by $t$ attributes and $m_{i}$ categories of the data under toroid coordinate systems. Unlike customary coding designs, the vector data puts it in basis of the $t$-dimensional toroid coordinate system, where basis is the smallest of the general number coordinate set, which it creates taking $m_{i}$ modulo addition. This scientific method reduces to the indexing $t$-dimensional data in the basis of $t$-dimensional toroidal reference system, where the basis is a set of less than the total number of coordinates of this coordinate set. Theoretically, is substantiated the existence of an infinitely large number of minimized basis, which give rise to numerous varieties of multidimensional "star" coordinate systems to find practical applications in modern and future multidimensional information technologies. Therefore, the proposed approach opens prospects for the development of the innovative information technologies grounded on the minimization of the basic structure of multidimensional coding systems and processing of big vector data in toroidal reference systems.

The subject of study is vector data coding methods of information under toroid coordinate systems. The known vector data coding methods [1-12] characterized by limited number of attributes and categories for signal coding and processing information encoded by two or more attributes and categories, as well as are high complexity.

The propose of the work is improving the efficiency of vector data coding methods and processing information encoded by two or more attributes and categories simultaneously.

\section{PROBLEM STATEMENT}

Mathematical problem in straight and inverse staging is reduced to establishing a mutually unambiguous display of vector binary code combinations sets according to vector data attribute-categories sets on the coordinate grid of the $t$-dimensional surface of the toroid.

The task is to increase the number of code combinations of $t$-dimensional binary code for the formation of information parameters of signals by the number of attributes and categories in the basis of the outlined $t$-dimensional coordinate system. We require the code combinations enumerate the node points set of the toroid coordinate grid with corresponding size and dimensionality.

The input variables are the number $t$ attributes and the number of $m_{i}$ indexed categories $(i=1,2, \ldots t)$ of the attributes.

The output variable is the maximum number of binary code combinations taking account the number $t$ attributes, and the number of $m_{i}$ indexed categories $(i=1,2, \ldots, t)$ of the attributes and the number $R$ of different ways of encoding the equally indexed sets "attribute-category" in the basis of the outlined $t$-dimensional toroid coordinate system.

We require the set of the underlying vector data oneto-one corresponds to set of nodal point coordinates of $t$ -

(C) Riznyk V. V., 2021

DOI 10.15588/1607-3274-2021-2-15 dimensional toroidal coordinate system, using a sub-set of the set, and their combined sums for cover the set of the outlined system with the size of $m_{1} \times m_{2} \times \ldots \times m_{t}$, the set of coordinates, which correspond to the $t$-sets of information parameters, and the number $R$ of different ways of encoding the equally indexed sets "attributecategory" in the basis of the $t$-dimensional coordinate system of given sizes and dimensionality. The criterion to be, for example, increasing the level of data protection, crypto graphical and system security, while maintaining on code size looking for a favorable compromise between the contrary objectives.

There are other options for setting the task in theoretically defined limits of changing input and output variables. Thus formats of vector data and codes should be jointly designed to reach the best trade-off between performance and complexity for optimum processing information under toroid coordinate systems.

Therefore, it is advisable to formalize the relationships between the information parameters of vector data encoding systems and theoretical limitations for optimal solution of specific problems under toroid coordinate systems.

\section{REVIEW OF THE LITERATURE}

The main goal of modern information technology is development of effective BVD coding and processing, including large data amounts analysis. However, the design based on the traditional theory is not always applicable for multidimensional data processing. BVD often involve a number of factors, such as national defense, economic, and other indexes of infrastructure, which have led to difficulties in large-scale data processing. In recent times, a great number of new concepts, parallel algorithms, processing tools, platform, and applications are suggested and developed to improve the value of BVD [1-12]. Big spatial vector data management presented in global review [1]. A comprehensive survey of the existing techniques and technologies from both academia and industry given in [2]. The papers [3-5] present prospects and problems of BVD for distant sensing. A techniques for compose of a map procedure, which performs filtering, sorting, and a summary operations of BVD presented at the IEEE International Conferences on Data Engineering [6]. Developing a reversible rapid coordinate transformation BVD model for the cylindrical projection, we see in paper [7]. The paper [8] contains fast multidimensional ensemble empirical mode decomposition for the analysis of big spatial-temporal datasets. The geometric computing algorithms are always very complex and timeconsuming, which makes big spatial data processing very slow, or even impossible [9]. A framework that couples cloud and high-performance computing for the parallel map projection of vector-based big spatial data regarded in $[10,11]$. In the United States, large payer data amassed to explore large data to advance knowledge discovery in nursing methodologies, clinical trials and lab research [12]. The idea of topological coordinates for toroidal chemical structures is in agreement with describing the 
physics of toroidal confined plasmas [13]. The projection provides large-scale spatial modeling of BVD under a common coordinate system. However, algorithmic complexity of the map projections represents a pressing computational challenge.

Modern theory of combinatorial configurations are such spatial structures as perfect difference sets [14, 17], algebraic constructions based on cyclic groups in extensions of Galois fields [15], manifolds [16], structures connecting algebra through geometry [17]. Many scientists also have suggested that the entire universe is a torus. This notion used to help visualize aspects of higher dimensional toroidal spaces. It was the torus mathematical model useful for describe geometric objects in spatial coordinates. The torus topology is superior to geometry for describing such objects because relate with philosophical spatial relationships. In one dimension, a usual single-holed torus is the 1 - torus as a ring shape object. In two dimensions, we see a usual torus, also called the 2 - torus. In analogy with this concept, in three and more dimensions, the $t$-dimensional torus, or $t$ - manifold is an object that exists in dimension $t+1$. Regarding the remarkable properties and structural perfection of two-and three-dimensional numerical rings [18], models of optimal multidimensional coding systems [19], and GUS combinatorial configurations [20], easy to see their toroidal topological structure.

Research into the underlying coding methods under toroid coordinate systems provide an ability optimal coding of multidimensional signals and objects, decreasing information redundancy in increasing code size of vector data coding under limitation on word length and geometric dimensions of toroid coordinate grid for trade-off processing vector data arrays of given number attributes and categories. Therefore, the formalization of these relationships is of very need, because make it possibility finding optimal solution by required criterion.

\section{MATERIALS AND METHODS}

"Symmetry, as wide or as narrow as you may define its meaning, is one idea by which man through the ages has tried to comprehend and create order, beauty and perfection." H. Weyl.

Symmetry and asymmetry relation in geometric structure is the most familiar type of them. The more general meaning of symmetry-asymmetry is in combinatorial configurations as a whole. In this context, symmetries and asymmetries underlie some of the most profound results found in modern physics, including aspects of space and time [21]. Finally, discusses interpenetrating symmetry and asymmetry in the humanities, covering its rich and varied use in architecture, philosophy, and art. Space-time symmetries are features of space-time that described as exhibiting some form of symmetry [22].

Let us define the quant interval $\alpha_{\min }$ for finding basic harmonious relationship between $S$ - fold rotational symmetry and embedded into the symmetry asymmetry (Fig. 1).

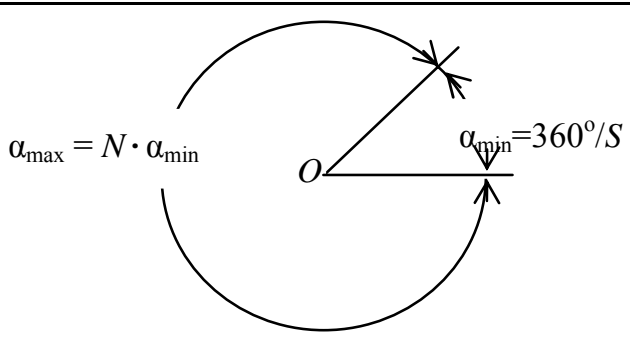

Figure 1 - A chart for define the quant interval $\alpha_{\min }$ for finding basic harmonious relationship between $S$ - fold rotational symmetry and embedded into the symmetry asymmetry

Definition. The $S$ - old rotational symmetry, which provides ability to split it into pairs of mutually complementary asymmetries, where we require a set of all $N=$ $(S-1) R=(n-1) n$ angular distances $\left[\alpha_{\min }, \alpha_{\max }\right]$. A set of angular spaces between everything possible lines that diverge from common center $O$ allows an enumeration of integers [1, $S-1]$ exactly $R$-times, is the Elegant Symmetry and Asymmetry Ensemble (ESAE) [19].

For example, the 7-fold $(S=7)$ rotational symmetry is the ESAE because splits into two mutually complementary asymmetries cyclically in ORS spatial proportions as both $\{1: 2: 4\}$ for the first, and the $\{1: 1: 3: 2\}$ - the second ones clockwise, where $\alpha_{\min }=360^{\circ} / 7, \alpha_{\max }=6 \alpha_{\min }$. In turn, the first of them is the IRB $\{1,2,4\}$ with $n=3$, $R=1$, while the second is the $\operatorname{IRB}\{1,1,3,2\}$ with $n=4$, and $R=2$.

From the Fig. 1 and underlying definition follows formula (1):

$$
S-1=\frac{n \cdot(n-1)}{R} \text {. }
$$

Note, the role of symmetry in physics is important in simplifying solutions to many problems, e.g. exact solutions of Einstein's field equations of general relativity [23], and study of isometrics in two or three-dimensional Euclidian space [24]. Only one angular interval in onefold $(S=1)$ rotational symmetry enumerates the set $\{1\}$ exactly once $(n=1)$ is singleton, known as a unit set [25].

The idea of "perfect" systems comes from remarkable properties of symmetry in combinatorics [14], and nature laws $[21,22]$. Let us regard the $n$-stage ring sequence of two-dimensional $(t=2)$ vectors with non-negative integers $\left\{\left(k_{11}, k_{12}\right),\left(k_{21}, k_{22}\right), \ldots,\left(\mathrm{k}_{i 1}, k_{i 2}\right), \ldots,\left(k_{n 1}, k_{n 2}\right)\right\}$, which form two-dimensional coordinate grid of sizes $m_{1} \times m_{2}$ over of a torus, taking modulo $m_{1}$, and modulo $m_{2}$ sums accordingly. The coordinate grid basis is "Glory to Ukraine Star" (GUS) combinatorial configurations [20].

Because "perfect" toroidal codes" created by GUS configurations, we call their, shortly, star-codes.

Planar projection of spatially disjointed the ring axes $m_{1}=2$ and $m_{2}=3$ coordinate points of two-dimensional $(t=2)$ toroid grid $m_{1} \times m_{2}=2 \times 3$ with common reference point $(0,0)$ given in Fig. 2. 


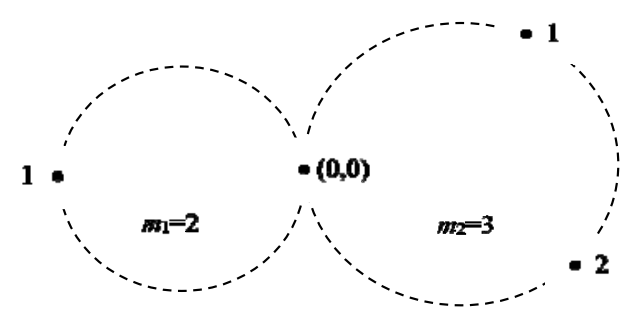

Figure 2 - Planar projection of spatially disjointed the ring axes $m_{1}=2$ and $m_{2}=3$ coordinate points of two-dimensional $(t=2)$ toroid reference grid $m_{1} \times m_{2}=2 \times 3$ with common reference point $(0,0)$

Hence, we have designed toroid coordinate system for vector data coding two $(t=2)$ attributes with two $\left(m_{1}=2\right)$ categories of the first, and three $\left(m_{2}=3\right)$ for the second attribute accordingly under star-code basis.

Next, we consider a more general model of the $t$-dimensional toroid coordinate system for vector data coding more of two attributes with arbitrary number of categories under star-code basis.

Clearly, a $t$-dimensional toroid coordinate system designed for vector data coding $t$ attributes and $m_{i}$ categories of each of them $(i=1,2, \ldots, t)$ requires $t$ concurrent disjointed axes $m_{1}, m_{2}, \ldots, m_{i}, \ldots, m_{t}$ with common reference point for forming $t$-dimensional coordinate grid of the system with sizes $m_{1} \times m_{2} \times \ldots \times m_{t}$. So, the underlying multidimensional information toroid coordinate system can be described by parameters $S, n, R, t, m_{\mathrm{i}}(i=1,2, \ldots, t)$. Here $t$ is dimension of vector data array, number of attributes, and number of significant digits of $t$-dimensional code, $m_{\mathrm{i}}$ is a number of categories of $i$-th attribute, and number of reference points on $i$-th ring axis in a toroidal coordinate system. Besides, information about vector data array depends of geometric sizes $m_{1} \times m_{2} \times \ldots \times m_{t}$, of the toroid coordinate system.

The harmonious relationship between $S$ - fold ESAE behavior is in agreement with classic combinatorial theory [14] based on algebraic group theory [17], and expands on the other combinatorial configurations [18-20] well.

Theorem. The maximum code size $P_{\max }$ of $n$-digit binary $t$ - dimensional star-code interconnected of numeric values $R, m_{1}, m_{2}, \ldots, m_{\mathrm{i}}, \ldots, m_{t}$ by the formula (2):

$$
\begin{gathered}
P \max =R \cdot \prod_{1}^{t} m_{i} \leq 2^{n}-1, \\
\left(m_{1}, m_{2}, \ldots, m_{i}, \ldots, m_{t}\right)=1
\end{gathered}
$$

Proof. The code size of $n$-digit binary code cannot be greater than the number of nonzero binary code combinations formed by it.

Corollary 1. The maximum code size $P_{\max }$ of $n$-digit binary $t$-dimensional star-code is equal to the order $S$ of the rotating symmetry, which spatial field creates the toroid coordinate grid with sizes $m_{1} \times m_{2} \times \ldots \times m_{i} \times \ldots \times m_{t}$.

Corollary 2. If the difference between the numerical values of the left and right parts of inequality (2) reduce, the star-code size increases, but security of the code is lost, and vice versa.

Corollary 3. Increasing the sizes of the $t$-dimensional toroidal coordinate grid allows intensification the converting form of vector data information with star-code, expanding the possibility of spatial reconstructing the coordinate system by combining the ratio between numerical values of interconnected formula (2).

Corollary 4. The star-code information capacity is the bigger than code size of it.

Application of the underlying relationships between the information parameters of vector data encoding systems and theoretical limitations for optimal solution of specific problems under toroid coordinate systems will make it possible to reach the best trade-off between performance and complexity for optimum processing information under toroid coordinate systems.

\section{EXPERIMENTS}

Experimental verification of the effectiveness of this information technology relates to optimization of vector data coding and processing under toroidal coordinate system, using novel designs based on the remarkable properties of ESAE, and the generalization of these methods and results to the improvement of a larger class of information systems.

The basic ideas of BVD processing under toroidal coordinate system are as following:

- determine sizes of toroidal coordinate system and its dimensionality accordingly to entity-attribute-value of a BVD list

- make indexing entity-attribute-value list under the toroidal coordinate system;

- fetch from an information base applicable vector star-code with respect to computer power and processing program;

- make Big Vector Data processing under the star toroidal coordinate system.

The efficiency is that the less number of encoded signals use for given vector data processing than at present, while maintaining on the other significant operating characteristics of the coding system underlying methods provide opportunities to apply them to configure suitable relation big vector data models, e.g., using $t$ attributes, and $m_{\mathrm{i}}$ categories for $i$-th attribute, $i=1,2, \ldots, t$ of the model.

Let us form toroid coordinate system for vector data coding two $(t=2)$ attributes with two $\left(m_{1}=2\right)$ categories of the first, and three $\left(m_{2}=3\right)$ for the second attribute accordingly under star-code basis. For example, 2-tuple set of three $(n=3)$ integer of the IRB $\{1,2,4\}$ forms modulo- 2 and modulo- 3 accordingly the basis $\{(1,1)$, $(0,2),(0,1)\}$ of two-dimensional $(t=2)$ toroid coordinate system as follows: $(0,0) \rightarrow(0,2)+(0,1) ;(1,0) \rightarrow(1,1)+$ $(0,2) ;(1,2) \rightarrow(0,1)+(1,1)$. Take the $\bmod _{1}(n-1)=\bmod _{1} 2$ sum of the ring axis $m_{1}=2$, and the $\bmod _{2} n=\bmod _{2} 3$ sum of the ring axis $m_{2}=3$. After arranged all vectors, we derive the coordinate grid $m_{1} \times m_{2}=2 \times 3$ over a torus based 
on the GUS $\{(1,1),(0,2),(0,1)\}$ exactly once $(R=1)$ (Table 1).

Table 1 - Forming the coordinate grid $m_{1} \times m_{2}=2 \times 3$ based on the GUS $\{(1,1),(0,2),(0,1)\}$

\begin{tabular}{|c|c|c|c|c|}
\hline \multirow{2}{*}{$№$} & \multicolumn{4}{|c|}{ Forming the reference grid $m_{1} \times m_{2}=2 \times 3$} \\
\cline { 3 - 5 } & \multirow{2}{*}{ References } & \multicolumn{3}{|c|}{ Summation the $\bmod _{1} 2$, and $\bmod _{2} 3$} \\
\cline { 3 - 5 } & $(1,1)$ & $(0,2)$ & $(0,1)$ \\
\hline 1 & $(0,0)$ & & + & + \\
\hline 2 & $(0,1)$ & & & + \\
\hline 3 & $(0,2)$ & & + & \\
\hline 4 & $(1,0)$ & + & + & \\
\hline 5 & $(1,1)$ & + & & \\
\hline 6 & $(1,2)$ & + & & + \\
\hline
\end{tabular}

From Table 1, easy to see the GUS $\{(1,1),(0,2),(0,1)\}$ forms the coordinate grid $2 \times 3$ over torus surface. The set of $2 \mathrm{D}$ coordinate grid one-to-one corresponds to a set of $2 \mathrm{D}$ vector data attributes, the first numerical index indicates vector data by two $\left(m_{1}=2\right)$ categories, while the second - three $\left(m_{2}=3\right)$ of ones by the same vector. The underlying property allows on $2 \mathrm{D}$ vector data processing over the $2 \times 3$ range concurrently.

Reasoning along similarly, we form toroid coordinate system for 2-tuple set of four $(n=4)$ integer for the IRB $\{1,1,3,2\}$ with $n=4, R=2$. We use the basis $\{(1,1)$, $(1,1),(1,0),(0,2)\}$ of $2 \mathrm{D}(t=2)$ toroid coordinate system: $(0,0) \rightarrow(1,1)+(1,0)+(0,2)$, and $(0,0) \rightarrow(1,0)+(0,2)+$ $(1,1) ;(0,1) \rightarrow(1,1)+(1,0)$, and $(0,1) \rightarrow(0,2)+(1,1)+$ $(1,1) ;(0,2)=(0,2)$, and $(0,2) \rightarrow(1,1)+(1,1) ;(1,0)=(1,0)$, and $(1,0) \rightarrow(0,2)+(1,1) ;(1,2) \rightarrow(1,0)+(0,2)$, and $(1,2)$ $\rightarrow(1,1)+(1,1)+(1,0)$. After arranged all vectors, we derive the coordinate grid $m_{1} \times m_{2}=2 \times 3$ over torus surface based on the GUS $\{(1,1),(1,1),(1,0),(0,2)\}$ exactly twice $(R=2)$ as shows in the Table 2 .

Table 2 - Forming the coordinate grid $m_{1} \times m_{2}=2 \times 3$ over torus based on the GUS $\{(1,1),(1,1),(1,0),(0,2)\}$

\begin{tabular}{|l|c|c|c|c|c|}
\hline \multirow{2}{*}{$№$} & \multicolumn{5}{|c|}{ Forming the reference grid $m_{1} \times m_{2}=2 \times 3$} \\
\cline { 2 - 6 } & & References & \multicolumn{3}{|c|}{ Summation the $\bmod _{1} 2$, and $\bmod _{2} 3$} \\
\cline { 3 - 6 } & & $(1,1)$ & $(1,1)$ & $(1,0)$ & $(0,2)$ \\
\hline 1 & $(0,0)$ & & + & + & + \\
\hline 2 & $(0,0)$ & + & & + & + \\
\hline 3 & $(0,1)$ & + & & & + \\
\hline 4 & $(0,1)$ & + & + & + & \\
\hline 5 & $(0,2)$ & & & + & + \\
\hline 6 & $(0,2)$ & + & + & & + \\
\hline 7 & $(1,0)$ & & & + & \\
\hline 8 & $(1,0)$ & & + & & + \\
\hline 9 & $(1,1)$ & + & & & \\
\hline 10 & $(1,1)$ & & + & & \\
\hline 11 & $(1,2)$ & & & + & + \\
\hline 12 & $(1,2)$ & + & + & & + \\
\hline
\end{tabular}

Generally, each $i$-th $t$-dimensional vector $K_{i}=\left(k_{i 1}\right.$, $\left.k_{i 2}, \ldots, k_{i t}\right)$ of $t$-dimensional sequence $\left\{K_{1}, K_{2}, \ldots, K_{i}, \ldots, K_{n}\right\}$

(C) Riznyk V. V., 2021

DOI 10.15588/1607-3274-2021-2-15 is a $t$-stage of non-negative integers as sub-sequence of the sequence, a set of ordered vector data attributes are indicated accordingly to $t$ categories of the BVD processing under $t$-dimensional toroidal coordinate system over coordinate grid $m_{1} \times m_{2} \times \ldots \times m_{t}$.

\section{RESULTS}

Fragments of the results of conducted experiments presented in the Tables 3-6.

Let us consider some specific examples using the methods for coding vector data sets of a particularly defined value in the basis of toroidal coordinate systems with corresponding geometric dimensions in the formalization (2).

The Table 3 contains six $\left(n^{2}-n=6\right) 3$-digit $(n=3)$ binary $2 \mathrm{D}(t=2)$ star-code combinations, which interrelated with numerical values of indexed vector data in the a priori of acceptable limits of their changes (2). In the Table 3 shows that the code size $P_{\max }$ of 3 -digit $(n=3)$ binary $2 \mathrm{D}(t=2)$ star-code comes near theoretically maximum, as basis of the toroid coordinate grid with sizes $m_{1}$ $\times m_{2}=(n-1) n=2 \times 3$ created under the first embedded into of the ESAE asymmetry, namely the GUS $\{(0,1)$, $(0,2),(1,0)\}$.

Table 3 - The forming 3-digit 2D star-code $\{(0,1),(0,2)$, $(1,0)\}$ under torus coordinate system $2 \times 3$

\begin{tabular}{|l|c|c|c|c|}
\hline \multirow{2}{*}{ № } & \multicolumn{4}{|c|}{ The 3-digit 2D star-code under grid $m_{1} \times m_{2}=2 \times 3$} \\
\cline { 2 - 5 } & \multirow{2}{*}{ Vector data } & \multicolumn{3}{|c|}{ Digit weights of the binary star-code } \\
\cline { 3 - 5 } & & $(0,1)$ & $(0,2)$ & $(1,0)$ \\
\hline 1 & $(0,0)$ & 1 & 1 & 0 \\
\hline 2 & $(0,1)$ & 1 & 0 & 0 \\
\hline 3 & $(0,2)$ & 0 & 1 & 0 \\
\hline 4 & $(1,0)$ & 0 & 0 & 1 \\
\hline 5 & $(1,1)$ & 1 & 0 & 1 \\
\hline 6 & $(1,2)$ & 0 & 1 & 1 \\
\hline
\end{tabular}

The Table 4 contains 12 binary 2D $(t=2)$ 4-digit $(n=4)$ combinations $\left(n^{2}-n=12\right)$ for coding two attributes $(t=2)$ both with two $\left(m_{1}=2\right)$ category of the first, and three $\left(m_{2}=3\right)$ - the second attribute concurrently.

Table 4 - The fragment of forming 4-digit 2D star-code $\{(1,1),(1,1),(0,2),(1,0)\}$ under torus coordinate system $2 \times 3$

\begin{tabular}{|l|c|c|c|c|c|}
\hline \multirow{2}{*}{ № } & \multicolumn{5}{|c|}{ The 4-digit 2D star-code under grid $m_{1} \times m_{2}=2 \times 3$} \\
\cline { 2 - 6 } & \multirow{2}{*}{ Vector data } & \multicolumn{4}{|c|}{ Digit weights of the binary star-code } \\
\cline { 2 - 6 } & & $(1,1)$ & $(1,1)$ & $(0,2)$ & $(1,0)$ \\
\hline 1 & $(0,0)$ & 0 & 1 & 1 & 1 \\
\hline 2 & $(0,0)$ & 1 & 0 & 1 & 1 \\
\hline 3 & $(0,1)$ & 1 & 0 & 0 & 1 \\
\hline 4 & $(0,1)$ & 1 & 1 & 1 & 0 \\
\hline$\ldots \ldots \ldots \ldots \ldots \ldots \ldots \ldots \ldots \ldots \ldots \ldots \ldots \ldots \ldots \ldots \ldots$ & $\ldots \ldots \ldots$ \\
\hline 14 & $(1,2)$ & 0 & 0 & 1 & 1 \\
\hline 15 & $(1,2)$ & 1 & 1 & 0 & 1 \\
\hline
\end{tabular}


In the Table 4 shows that the code size $P(n)=2^{n}-1=15$ of 4 -digit $(n=4)$ binary $2 \mathrm{D}(t=2)$ starcode with $n=4$ and $R=2$. Note, the basis of the toroid coordinate grid created under the second embedded into of the ESAE asymmetry, namely the GUS $\{(1,1),(1,1)$, $(1,0),(0,2)\}$.

Table 5 illustrates fragment of forming 4-digit 2D star-code $\{(1,2),(2,4),(1,3),(2,1)\}$ under torus coordinate system $3 \times 5$. In the Table 5 shows that the code size $P(n)$ $=2^{n}-1=15$ of 4 -digit $(n=4)$ binary $2 \mathrm{D}(t=2)$ star-code with $n=4$ and $R=1$. Note, the basis of the torus coordinate grid created under the GUS $\{(1,2),(2,4),(1,3)$, $(2,1)\}$.

Table 5 - The fragment of forming 4-digit 2D star-code $\{(1,2)$,

\begin{tabular}{|c|c|c|c|c|c|}
\hline \multirow{3}{*}{ № } & \multicolumn{5}{|c|}{ The 4-digit 2D star-code under grid $m_{1} \times m_{2}=3 \times 5$} \\
\hline & \multirow{2}{*}{ Vector data } & \multicolumn{4}{|c|}{ Digit weights of the binary star-code } \\
\hline & & $(1,2)$ & $(2,4)$ & $(1,3)$ & $(2,1)$ \\
\hline 1 & $(0,0)$ & 1 & 1 & 1 & 1 \\
\hline 2 & $(0,1)$ & 1 & 1 & 0 & 0 \\
\hline 3 & $(0,2)$ & 0 & 1 & 1 & 0 \\
\hline 4 & $(0,3)$ & 1 & 0 & 0 & 1 \\
\hline \multicolumn{6}{|c|}{ 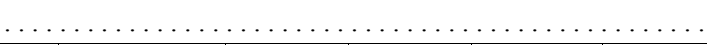 } \\
\hline 14 & $(2,3)$ & 0 & 1 & 1 & 1 \\
\hline 15 & $(2,4)$ & 0 & 1 & 0 & 0 \\
\hline
\end{tabular}

In the Table 6 shows forming 5-digit 2D star-code $\{(1,1),(1,4),(2,2),(2,2),(2,3)\}$ under torus coordinate system $3 \times 5$. To see this we observe that the code size $P$ $(n)=2^{n}-1=31$ of 5 -digit $(n=5)$ binary $2 \mathrm{D}(t=2)$ starcode with $n=5$ and $R=2$. Note, the basis of the torus coordinate grid created under the GUS $\{(1,1),(1,4),(2,2)$, $(2,2),(2,3)\}$.

Table 6 - The fragment of forming 5-digit 2D star-code $\{(1,1),(1,4),(2,2),(2,2),(2,3)\}$ under coordinate system $3 \times 5$

\begin{tabular}{|c|c|c|c|c|c|c|}
\hline \multirow{3}{*}{ № } & \multicolumn{6}{|c|}{ The 5-digit 2D star-code under grid $m_{1} \times m_{2}=3 \times 5$} \\
\hline & \multirow{2}{*}{$\begin{array}{l}\text { Vector } \\
\text { data }\end{array}$} & \multicolumn{5}{|c|}{ Digit weights of the binary star-code } \\
\hline & & $(1,1)$ & $(1,4)$ & $(2,2)$ & $(2,2)$ & $(2,3)$ \\
\hline 1 & $(0,0)$ & 1 & 1 & 0 & 1 & 1 \\
\hline 2 & $(0,1)$ & 1 & 1 & 1 & 0 & 1 \\
\hline 3 & $(0,2)$ & 0 & 1 & 1 & 0 & 0 \\
\hline 4 & $(0,3)$ & 0 & 1 & 0 & 1 & 0 \\
\hline \multicolumn{7}{|c|}{ 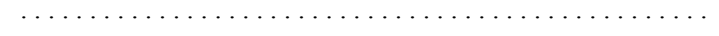 } \\
\hline 30 & $(2,3)$ & 0 & 1 & 0 & 1 & 1 \\
\hline 31 & $(2,4)$ & 0 & 1 & 1 & 0 & 1 \\
\hline
\end{tabular}

From the Tables 3-6 follows that the underlying formula (2) make it possible to reach the best trade-off between performance and complexity for optimum processing of information under toroid coordinate system, while maintaining or improving on information capacity of the system.

The equations (1) and (2) formalize a large class of $t$ dimensional codes from non-redundant vector codes of high performance [19] to coding self-correcting vector

(C) Riznyk V. V., 2021

DOI 10.15588/1607-3274-2021-2-15 data signals with faster than classic codes transmission of multidimensional information by noise communication channels [20]. One of them is optimum binary monolithic star-code for processing of two-or multidimensional vector signals under toroidal coordinate system. The monolithic star-code forms code combinations as a sequence of solid connected symbols " 1 " or " 0 " in the code combination $[19,20]$. This property makes it possible to use selfcorrecting vector data signals for faster than classic codes transmission in a noise channel, using limited number of bits.

From the underlying formalization (1) and (2) have been defined the next types of the optimum weighed $n$ digital binary ring monolithic codes based on IRBs [20]:

a) numerical code is a set of ring $n$-sequences of positive integers which sums of connected sub-sequences of the set enumerate the set of integers $[1, N]$ exactly $R$ times, $N=n(n-1) / R$;

b) two-dimensional code is a set of ring $n$-sequences of 2-tuple nonnegative integers which modular sums of connected 2-tuple taken modulo $m_{1}$ and $m_{2}$, respectively, allows an enumeration of nodal points of coordinate grid $m_{1} \times m_{2}$ over 3 -torus exactly $R$-times with frame of axes $m_{1} \cdot m_{2}=n(n-1) / R$

c) multidimensional code is a set of ring $n$-sequences of $t$-tuple nonnegative integers which modular sums of connected $t$-tuple taken modulo $m_{1}, m_{2}, \ldots, m_{t}$, respectively, allows an enumeration of nodal points of coordinate grid $m_{1} \times \ldots \times m_{t}$ over $(t+1)$-torus exactly $R$-times with frame of axes $m_{1} \cdot m_{2} \ldots \cdot m_{t}=n(n-1) / R$.

\section{DISCUSSION}

As it evident, the Table 3 demonstrates the advantages of two-dimensional $(t=2)$ binary vector data coding in the minimized 3-digit $(n=3)$ 2D database of the toroid coordinate system a reference grid with sizes $m_{1} \times m_{2}=2 \times 3$. The mutually unambiguous compliance with a set of indexed data "attribute-categories" of a set of binary vector code combinations formed by this database have been achieved in the system. In turn, it was possible due to reducing the natural redundancy in the system.

Instead, Table 4 gives example of the introduction of artificial redundancy by increasing to two $(R=2)$ the number of ways to cover the grid for increasing 2 times security of the vector data, due to increment a register capacity by one: from $n=3$ to 4 . According to the formula (1) the sizes of reference grid are the same that for the parameters $S=7, n=3, R=1$ because $S=7, n=4$, $R=2$, and consequently $m_{1} \times m_{2}=2 \times 3$ also.

Reasoning along similarly, in the Tables 5 and 6 show methods of vector data coding design in the minimized database of the toroid coordinate system a reference grid with sizes $m_{1} \times m_{2}=3 \times 5$.

In the formula (2), the underlying rule displayed by the number $R$ of methods of covering all node points of $t$-dimensional outlined toroidal coordinate system for encoding of indexed vector data "attribute-categories" sets with $t$ attributes and appropriated number of categories in the set. Besides, using $n$-digit base reconstruction of $t$ - 
dimensional binary vector provide code we the rule: repetition is a loss of information in order to increase so-many times security of vector data coding under the coordinate system. In addition, there are elegant ensembles of starcodes, which allow you to form different sets of allowed code combinations on a set of modular sums of the base vectors of the toroid coordinate system according to several ring schemes with cross routes of their bypass $(R=1)$ or more $(R>1)$ in ways [18-20]. From the formula (1) and (2) follows increasing the number of allowed code combinations of the coding method and improving the characteristics of vector data encoding in toroid coordinate systems by performance and interference, as well as the star-code information capacity increases faster than code size of the code with growing dimensionality and number of its binary digits.

The study aims at patterns of transformation of flat harmoniously conjugated asymmetric structures of rotating symmetry into spatial structural forms of higher dimensions, where they take the form of two-and multidimensional toroid coordinate systems formed by a minimized binary code basis with vector weight digits. Such combinatorial configurations differ favorably from the classical ones [14-18] of spatial forms with central, mirror or axial symmetries, forming families on a set of the ESAEs with varieties of symmetrical shape [19].

The growth of vector code combination by one bit doubles the code size of the encoding method in the outlined toroid coordinate system with the corresponding dimensions and dimensions. The number of indexed attributes and categories in the form of any long a priori of integer $t$-tuple allows one code word to encode, forward and process in the basis of the system simultaneously as many signs of vector data as symbols contained in the $t$ tuples. It respectively provides increasing the performance of the system at $t$ times, where $t$ is the number of ring axes of the toroid coordinate grid.

Formalization allows you to reach a balanced compromise on contradictory goals related to the power and reliability of the information method. It outlines theoretically a large-scale information model of harmoniously built of multidimensional geometric space as a hypothetical system of a perfectly structured source of information as $t$-dimensional locked spheres. This system has a priori infinitely large number of sets of coordinate sub-systems of quantum "density", generated by a minimized basis of $t$-dimensional binary $n$-bit code with compression coefficient value approaching to $2^{n} / n$.

Formalization of methods of optimal encoding of multidimensional data arrays in spatial coordinate systems is connected not only with the establishment of mathematical connection of information parameters with harmoniously organized symmetrical and asymmetric spatial structures, but also with the processing of a set of philosophical, methodological, scientific and applied, educational problems of analysis and synthesis of multidimensional information systems.

Among other results, it is interesting to observe the behavior of mathematical models of geometric objects (C) Riznyk V. V., 2021

DOI 10.15588/1607-3274-2021-2-15 with non-uniform structure [18-20]. These objects can be in progress for originate of such geometric structures already in the higher dimensions, with the advent of new elegant forms of spatial configurations enriched with numerous varieties of thin structure multiplied on growing of their combinatorial varieties. It follows an intuitive conclusion about the hypothetical model of toroidal geometric structure in the behavior of natural and man-made objects in the real world $[21,22]$.

\section{CONCLUSIONS}

The urgent problem of coding and processing large information content solved, using formalization of interdependence between information parameters of vector data coding systems on a single mathematical platform. The study of the theoretical relationship between the detected pattern of harmonious conjuring of symmetrical and asymmetrical structures, the basic principle of optimal structural relations (OSR) was established. It reflects the essence of the proposed concept of converting multidimensional form of information with binary code in a structured field of toroid coordinate systems of corresponding dimensions and dimensionalities for provide optimum coding and processing vector data arrays with numbering attributes and categories under minimized basis of outlined $t$-dimensional toroidal coordinate system, using the underlying formalization (1), (2).

The scientific novelty of obtained results is the formalization of interdependence between information parameters of vector data coding systems on a single mathematical platform. This approach allows forming the outlined $t$-dimensional toroidal coordinate system, using smaller as all number of coordinates set basis of $t$-tuples. This, in turn, provides optimum coding and processing vector data arrays with numbering attributes and categories under minimized basis of outlined $t$-dimensional toroidal coordinate system by holding criterion and limitations to achieve a favorable compromise between contradictory goals in changing of computational values within of theoretically defined by formulas (1) and (2) boundaries. The upper limit of the information capacity encoding method for given code size and numbering attributes, and categories of vector data sets, as well as $R$ of various ways of coding the same "attribute-category" sets defined.

Prospect for further research are the development of new direction in multidimensional systems engineering, for improving such quality indices as information capacity, reliability, transmission speed, positioning precision, and ability to reproduce the maximum number of combinatorial varieties in the system with a limited number of elements and bonds, using remarkable properties and structural perfection of GUS combinatorial configurations. The experimental results allow recommending the proposed methodology for direct applications to information and computational technologies, telecommunications, radio-and electronic engineering, radio-physics, and other engineering areas, as well as in education. These design techniques allows configure optimum two-and multidimensional vector data coding system, using innovative 
methods based on the underlying combinatorial models offering ample scope for progress in systems engineering, cybernetics, and industrial informatics.

Physical results - a better understanding the role of geometric structure in the behavior of natural and manmade objects.

The existence of an a priori of an infinitely large number of minimized basis, which give rise to numerous varieties of multidimensional "star" coordinate systems, opens up new possibilities for solving a wide range of mathematical and applied problems of computer science, cybernetics, and management on the platform of system mathematics. We take into account the developments of modern theory of systems as a set of philosophical, methodological and scientific, and applied problems of analysis and synthesis of multidimensional systems.

A perfection and harmony exists not only in the abstract models but in the real world also.

\section{ACKNOWLEDGEMENTS}

This work involves the results performed in 20122017 years in Automated Control Systems Department of Lviv Polytechnic National University. I grateful to our colleagues for their active participation in support and understanding important significance in development of fundamental and applied research in vector information technologies, using design based on multidimensional combinatorial optimization of the technology. The basic results of the research presented in completed work on the R\&S project "Designing Software for Vector Data Processing and Information Protection Based on Combinatorial Optimization" (State registration 0113U001360). State account number 0218U000988. All authors declare that no have financial support.

\section{REFERENCES}

1. Xiaochuang Y., Guoqing $\mathrm{Li}$ Big spatial vector data management: a review, Big Earth Data, 2018, Vol. 2, No. 1, pp. 108-129. DOI: 10.1080/20964471.2018.1432115

2. Bose N. R. Applied Multidimensional Systems Theory. Pensilvania State University State College, PA, USA: Springer Int. Publishing AG, 2017, 192 p.

3. Chi M., Plaza A., Benediksson J. A., Chi M., Plaza A., Benediktsson J. A., Sun Z., Shen J., and Zhu Y. Big data for remote sensing: Challenges and opportuni ties, IEEE, 104 (11), pp. 2207-2219, DOI:10.1109/Jproc. 2016.598228

4. Ma Y., Wu H., Wang L., Huang B., Ranjan R., Zomaya A., Jie W. Remote sensing big data computing: Challenges and opportunities, Future Generation Computer Systems, 2015, No. 51, pp. 47-60. DOI:10.1016/j.future.2014.10.029

5. Pekturk M. K., Unal M. A review on real-time big data analysis in remote sensing applications, 25th Signal Processing and Communications Applications Conference (SIU). Antalya, Turkey, 15-18, May 2017.

6. Eldawy A., Mokbel M. F., Alharthi S., Alzaidy A., Tarek K., Ghani S. SHAHED A MapReduce-based system for querying and visualizing spatio-temporal satellite data, IEEE International Conference on Data Engineering. Seoul, South Korea, 13-17 April 2015.

7. Ye S., Yan T., Yue Y., Lin W., Li L., Yao X., Zhu D. Developing a reversible rapid coordinate transformation model for the cylindrical projection, Computers \&Geosciences, 89, pp. 44-56. DOI:10.1016/j.cageo.2016.01.007

8. Wu Z., Feng J., Qiao F., Tan M. Z. Fast multidimensional ensemble empirical mode decomposition for the analysis of big spatio-temporal datasets, Philos Trans A Math Phys Eng Sci., 2016, 374(2065), 2015.01.97

9. Ray S., Simion B., Brown A. D., Johnson R. A parallel spatial data analysis infrastructure for the cloud, $A C M$ SIGSPATIAL International Conference on Advances in Geographic Information Systems, 5-8 November 2013. Orlando, FL, USA.

10. Tang W., Feng W. Parallel map projection of vector-based big spatial data: Coupling cloud computing with graphics processing units, Computers, Environment and UrbanSystems, 2014, Vol. 61, pp. 187-197. DOI:10.1016/j.compenvurbsys.2014.01.001

11. Eldawy A., Mokbel M. F., Jonathan C. Hadoop Viz: A MapReduce framework for extensible visualization of big spatial data, The 32nd IEEE International Conference on Data Engineering, 16-20 May 2016. Helsinki, Finland, IEEE, 2016.

12. Connie DeLaney W., Charlotte Weaver A., Judith Warren J., Thomas Clancy R., Roy L. SimpsonBig Data-Enabled Nursing: Education, Research and Practice. Cham, Switzerland, $\quad$ Springer, 2017, 488 p. https://www.bookdepository.com/Big-Data-EnabledNursing-Connie-White-Delaney/9783319532998

13. Laszlo I., Rassat A., Fowler P. W., Graovas A. Topological coordinates for toroidal structures, Chemical Physics Letters: Elsevier Science B. V, 2001, Vol. 342, pp. 369-374.

14. Hall Jr. Combinatorial Theory, 2 edition, WileyInterscience, 1998, 464 p. DOI: 10.1002 / 9781118032862

15. Rotman Joseph. Galois Theory, Second ed.: Springer, 1998, 106 p. DOI:10.1007/978-1-4612-0617-0

16. Lee John M. Introduction to topological manifolds. Springer-Verlag, New York, Inc., 2000, 395 p. DOI: 10.1007 / 978-1-4419-7940-7

17. Moore E. H., Pollatsek H. S. Difference Sets, Student mathematical library Volume 67: Connecting Algebra, Combinatorics, and Geometry, AMS, 2013, 298 p. ISBN 978-0-8218-9176-6

18. Riznyk W. Application of the Golden Numerical Rings for Configure Acoustic Systems of Fine Resolution, Acta Physica Polonica A., 2011, Vol. 119, pp. 1046-1049. DOI: 10.12693/APhysPolA.119.1046

19. Riznyk V. Multi-modular Optimum Coding Systems Based on Remarkable Geometric Properties of Space, Advances in Intelligent Systems and Computing. Springer, 2017, Vol. 512, pp. 129-148. DOI 10.1007/978-3-319-45991-2 9

20. Riznyk V. V. Multidimensional Systems Optimization Developed from Perfect Torus Groups, International Journal of Applied Mathematics and Informatics, 2015, Vol. 9, pp. 5054.

21. Weyl Hermann. Symmetry. New Jersey, Princeton University Press, Princeton, 1952, 175 p.

22. Wigner Eugen P. Symmetries and reflections. Bloomington, Indiana University Press, 1967, 280 p.

23. Spacetime_symmetries [Electronic resource]. Access mode:https://en.wikipedia.org/wiki/Spacetime_symmetries.

24. Euclidian group [Electronic resource]. Access mode: https://en.wikipedia.org/wiki/Euclidian group.

25. Singleton (mathematics) [Electronic resource].-Access mode: https://en.wikipedia.org/wiki/Singleton (mathematics) Received 07.12.2020. Accepted 18.04.2021. 


\section{ФОРМАЛІЗАЦІЯ МЕТОДІВ КОДУВАННЯ ІНФОРМАЦІЇ В ТОРОЇДНИХ СИСТЕМАХ КООРДИНАТ}

Різник В. В. - д-р техн. наук, професор, професор кафедри автоматизованих систем управління Національного університету «Львівська політехніка», Львів, Україна.

\section{АНОТАЦІЯ}

Актуальність. Кодування та опрацювання великого інформаційного контенту актуалізує проблему формалізації взаємозалежності між інформаційними параметрами систем кодування векторних даних на єдиній математичній платформі. Об’єктом дослідження є модель кодування масивів векторних даних в базисі тороїдних систем координат. Мета роботи формалізація методів кодування векторних даних в оптимізованому базисі тороїдних систем координат.

Метод. В основу дослідження покладено встановлений факт гармонійного спряження симетричних та асиметричних структур у вигляді оптимальних співвідношень між симетрією і вбудованими в неї асиметричними просторовими структурами з груповими властивостями, притаманними для векторних комбінаторних конфігурацій «зіркового» класу - наборів $t$ вимірних векторів двійкового коду як базису $t$-вимірної системи координат тороїда. Для опису математичної моделі «зіркових» систем координат використано математичний апарат теорії множин, теоретико-числові і теоретико-групові методи комбінаторного аналізу та елементи алгебричної теорії ідеальних кільцевих в'язанок. Метод дозволяє формалізувати взаємозв'язок інформаційних параметрів векторного коду (число кодових комбінацій, розрядність, кількість способів кодування однакових наборів) з геометричними параметрами системи координат (розмірність і розміри сітки по числу атрибутів і категорій векторних даних). Виведено функціональну залежність між вищезгаданими параметрами, що дозволяє досягати вигідного компромісу між суперечними цілями (наприклад, продуктивністю і надійністю методу кодування).

Результати. Розроблені методи реалізовані при оптимальному кодуванні векторних даних в базисі тороїдних систем координат.

Висновки. Проведені обчислювальні експерименти підтвердили працездатність запропонованого математичного забезпечення і дозволяють рекомендувати його для використання на практиці при вирішенні задач формалізації методів оптимального кодування масивів векторних даних та опрацювання інформації різної природи в тороїдних системах координат визначених розмірів і розмірності.

КЛЮЧОВІ СЛОВА: елегантний ансамбль симетрії - асиметрії, закономірність, інформаційна надмірність, комбінаторна конфігурація, оптимальне кодування векторних даних, потужність коду, базис, компроміс.

\section{УДК 621.396:519.15}

\section{ФОРМАЛИЗАЦИЯ МЕТОДОВ КОДИРОВАНИЯ ИНФОРМАЦИИ В ТОРОИДНЫХ СИСТЕМАХ КООРДИНАТ}

Ризнык В. В. - д-р техн. наук, профессор, профессор кафедры автоматизированных систем управления Национального университета «Львівська політехніка», Львов, Украина.

\section{АННОТАЦИЯ}

Актуальность. Кодирование и обработка большого информационного контента актуализирует проблему формализации взаємозависимости между информационными параметрами систем кодирования векторных данных на единой математической платформе. Объектом исследования является модель кодирования массивов векторных данных в базисе тороидных систем координат. Цель работы - формализация методов кодирования векторных данных в оптимизированном базисе тороидных систем координат.

Метод. В основу исследования положено установленный факт гармонического сопряжения симметричных и асимметричных структур в виде оптимальных соотношений между симметрией и встроенной в нее ассиметричными просторанственными структурами с групповыми свойствами, присущими для векторных комбинаторных конфигураций «звездного» класса - наборов $t$-мерных векторов двоичного кода как базиса $t$-мерной системы координат тороида. Для описания математической модели «звездных» систем координат использован математический аппарат теории множеств, теоретикочисловые и теоретико-групповые методы комбинаторного анализа и элементы алгебраической теории идеальных кольцевых вязанок. Метод позволяет формализовать взаимосвязь информационных параметров векторного кода (число кодовых комбинаций, розрядность, количество способов кодирования одинаковых наборов) с геометрическими параметрами системы координат (размерность и размеры сетки по числу атрибутов и категорий векторных данных). Выведено функциональную зависимость между вышеупомянутыми параметрами, что позволяет достигать выгодного компромисса между противоречивыми целями (например, производительность и надежность метода кодирования).

Результаты. Разработаны методы и реализованы при оптимальном кодировании векторных данных в базисе тороидных систем координат.

Выводы. Проведенные вычислительные эксперименты подтвердили работоспособность предложенного математического обеспечения и позволяют рекомендовать его для использования на практике при решении задач формализации методов оптимального кодирования массивов векторных данных и обработки информации различной природы в тороїдных системах координат определенных размеров и размерности.

КЛЮЧЕВЫЕ СЛОВА: элегантный ансамбль симметрия-асимметрия, закономерность, информационная избыточность, комбинаторная конфигурация, оптимальное кодирование векторных данных, мощность кода, базис, компромисс. 


\section{ЛІТЕРАТУРА / ЛИТЕРАТУРА}

1. Xiaochuang Y. Big spatial vector data management: a review / Y. Xiaochuang, Li Guoqing // Big Earth Data. 2018. - Vol. 2, № 1. - P. 108-129. DOI: 10.1080/20964471.2018.1432115

2. Bose N. R. Applied Multidimensional Systems Theory / N. R. Bose. - Pensilvania State University State College, PA, USA: Springer Int. Publishing AG, 2017. - 192 p.

3. Big data for remote sensing: Challenges and opportuni ties / [M. Chi, A. Plaza, J. A. Benediksson et al.] // IEEE. 104 (11). - P. 2207-2219. DOI:10.1109/Jproc. 2016.598228

4. Remote sensing big data computing: Challenges and opportunities / [Y. Ma, H. Wu, L. Wang, et al.] // Future Generation Computer Systems. - 2015. - № 51. - P. 47-60. DOI:10.1016/j.future.2014.10.029

5. Pekturk M. K. A review on real-time big data analysis in remote sensing applications / M. K. Pekturk, M. Unal // 25th Signal Processing and Communications Applications Conference (SIU), Antalya, Turkey, 15-18, May 2017

6. A MapReduce-based system for querying and visualizing spatio-temporal satellite data / [A. Eldawy, M. F. Mokbel, S. Alharthi et al.] // IEEE International Conference on Data Engineering, Seoul, South Korea, 13-17 April 2015.

7. Developing a reversible rapid coordinate transformation model for the cylindrical projection / [S.Ye, T. Yan, Y. Yue et al.] // Computers \&Geosciences. - 89 . - P. 44-56. DOI:10.1016/j.cageo.2016.01.007

8. Fast multidimensional ensemble empirical mode decomposition for the analysis of big spatio-temporal datasets / [Z. Wu, J. Feng, F. Qiao, Tan M. Z.] // Philos Trans A Math Phys Eng Sci. - 2016. - 374(2065), 2015.01.97

9. A parallel spatial data analysis infrastructure for the cloud / [S. Ray, B. Simion, A. D. Brown, R. Johnson] // ACM SIGSPATIAL International Conference on Advances in Geographic Information Systems, 5-8 November 2013. Orlando, FL, USA.

10. Tang W. Parallel map projection of vector-based big spatial data: Coupling cloud computing with graphics processing units / [W.Tang, W. Feng] // Computers, Environment and UrbanSystems. - 2014. - Vol. 61. - P. 187-197. DOI: 10.1016/j.compenvurbsys.2014.01.001

11. Eldawy A. Hadoop Viz: A MapReduce framework for extensible visualization of big spatial data / [A. Eldawy, M. F. Mokbel, C. Jonathan] // The 32nd IEEE International Conference on Data Engineering, 16-20 May 2016. - Helsinki, Finland: IEEE, 2016.
12. Big Data-Enabled Nursing: Education, Research and Practice / [W. Connie DeLaney, A. Charlotte Weaver, J. Judith Warren et al.]. - Cham, Switzerland : Springer, 2017. 488 p. https://www.bookdepository.com/Big-Data-EnabledNursing-Connie-White-Delaney/9783319532998

13. Topological coordinates for toroidal structures / [I. Laszlo, A. Rassat, P. W. Fowler, A. Graovas]] // Chemical Physics Letters: Elsevier Science B. V. - 2001. - Vol. 342. - P. 369374.

14. Hall Jr. Combinatorial Theory / Jr. Hall. -2 edition : WileyInterscience, 1998. - 464 p. DOI: 10.1002 / 9781118032862

15. Rotman Joseph. Galois Theory / Joseph Rotman. - Second ed.: Springer, 1998. - 106 p. DOI:10.1007/978-1-46120617-0

16. Lee John. Introduction to topological manifolds / John M. Lee. - Springer-Verlag, New York, Inc., 2000.395 p. DOI:10.1007 / 978-1-4419-7940-7

17. Emily H. Moore Difference Sets / Emily H. Moore, Harriet S. Pollatsek // Student mathematical library. - Connecting Algebra, Combinatorics, and Geometry. AMS. - 2013. Vol. 67. - 298 p. ISBN 978-0-8218-9176-6

18. Riznyk W. Application of the Golden Numerical Rings for Configure Acoustic Systems of Fine Resolution / W. Riznyk // Acta Physica Polonica A. - 2011. - Vol. 119. - P. 10461049. DOI: 10.12693/APhysPolA.119.1046

19. Riznyk V. Multi-modular Optimum Coding Systems Based on Remarkable Geometric Properties of Space / V. Riznyk // Advances in Intelligent Systems and Computing. - Springer, 2017. - Vol. 512. - P. 129-148. DOI 10.1007/978-3-31945991-2 9

20. Riznyk V. V. Multidimensional Systems Optimization Developed from Perfect Torus Groups / V. V. Riznyk // International Journal of Applied Mathematics and Informatics. 2015. - Vol. 9. - P. 50-54. ISSN: 2074-1278.

21. Weyl Hermann. Symmetry / Hermann Weyl. - New Jersey: Princeton University Press, Princeton, 1952. -175 p.

22. Wigner Eugen P. Symmetries and reflections/ Eugen P. Wigner. - Bloomington : Indiana University Press, 1967. $280 \mathrm{p}$.

23. Spacetime_symmetries [Electronic resource].-Access mode:https://en.wikipedia.org/wiki/Spacetime_symmetries

24. Euclidian group [Electronic resource].-Access mode: https://en.wikipedia.org/wiki/Euclidian group

25. Singleton (mathematics) [Electronic resource].-Access mode: https://en.wikipedia.org/wiki/Singleton (mathematics) 